\title{
I mpacto da violência na saúde de famílias em Fortaleza, Ceará
}

\author{
Impact of violence on the health of families at Fortaleza, Ceará State
}

Luiza Jane Eyre de Souza Vieira ${ }^{1}$

M árcia Liduína Vasconcelos Arcoverde ${ }^{1}$

Maria Alix Leite Araújo ${ }^{1}$

Renata Carneiro Ferreira ${ }^{1}$

Ana Virgínia de M elo Fial ho ${ }^{2}$

Augediva M ariaJucá Pordeus ${ }^{1}$

${ }^{1}$ Centro de Ciências da

Saúde, M estrado em Saúde

Coletiva. Universidade de

Fortaleza, UNIFOR. Av.

Washington Soares, 1321,

Edson Queiroz,

60811-905, Fortaleza,

Ceará. janeeyre@unifor.br

${ }^{2}$ Centro deCiências da

Saúde, Universidade

Estadual do Ceará.
Abstract The study describes the impact of the violence on the quality of life of the families, which were attended at the Relatives and Friends Violence Victims A ssociation (ARFVV) in Fortaleza, Ceará State. The case study was accomplished among five mothers that wereinvolved in a NGO on the battleagainst the violence. The semi-structured interview, the participation at the institution's meetings and the documental research were the data collecting techniques, being these last ones, submitted to the thematic analysis and discussed according to the literature and Letters of $\mathrm{H}$ ealth Promotion. The impacts caused by the violence comprise the physical, emotional and social family's health, cause changes on behavior be tween the members, and lead to the increasing of smoking, drinking, social isolation and exacerbate revolt feelings, vengeanceand pessimism. The NGO's work has been important to support the families on the conflicts overcoming, health familiar restoration, redeeming the self-expectation, the hope on the jus tice and social mobility. The health of families' victims from violence is affected on the biological, emotional and social aspects, favoring the process of sickness. These have appealed to the support from NGOs to transform the "victim condition" - violence hostage to the "responsible citizenship" - guardians of peace on the battle against the urban violence. Key words Violence, Health, Family, NGO
Resumo 0 estudo descreve 0 impacto da violência na qualidade de vida de famílias atendidas na Associação de Parentes e Amigos Vítimas da Violência (APAVV), em Fortaleza, Ceará. Estudo decaso realizado com cinco mãesqueparticipavam deuma ONG no combate à violência. A entrevista semi-estruturada, partici pação nas reuniões da insti tuição e pesquisa documental foram as técnicas de coleta de dados, sendo esses últimos submeti dosà análisetemática e discutidos à luz da literatura e das cartas de promoção da saúde. Os impactos causados pela violência comprometem a saúde física e emocional das famílias, originam mudanças de comportamento entre os membros, contribuem para o aumento do tabagismo, do etilismo, do isolamento social e exacerbam sentimentos de revolta, vingança e pessimismo. 0 trabalho da ONG tem sido importante para apoiar as famílias na superação dos conflitos e na restauração da saúde, resgatando a auto-estima, a esperança na justiça ena mobilidade social. A saúde dessas famílias fica comprometida nos aspectos biológicos, emocionais e sociais, favorecendo 0 adoecimento. Essastêm recorrido ao suporte deO N Gs para transformarem a "condição de vítima" - refém da violência - em "cidadania responsável" na luta contra esse fenômeno.

Palavras-chave Violência, Saúde, Família, ONG 
Introdução

A violência vem setornando um ônus significativo para as populações de todo o mundo e diminuir sua morbidade e mortalidade é um dos principais desafios para as autoridades epara a sociedade (saúdepública). Embora degrandecomplexidade, éum problema que pode ser compreendido emudado ${ }^{1,2}$.

Nessa perspectiva, desde o início da década de oitenta, o campo da saúde pública tem dado uma importante contribuição nessa resposta e profissionais, pesquisadores e sistemas de saúde tomaram para si as tarefas de entender as raízes da violência e evitar sua ocorrência ${ }^{3,4}$.

A violência cresce e interfere no cotidiano dos brasileiros, sobretudo daqueles que habitam nas áreas urbanas, sem negar que essa também atingiu as zonas rurais. Paralelamente, aumenta a demanda da sociedade por segurança pública; porém, em qualquer uma das esferas do governo, não é fácil encontrar soluções gerais e permanentes para essa questão, isso porque não existe apenas a "violência", mas diversas "violências", referidas a diferentes contextos e situações ${ }^{5}$.

Estudos sinalizam que 0 aprofundamento das desigualdades sociais é um dos principais fatores para a explicação do aumento da violência urbana, por causar consequências desastrosas, como o aumento da criminalidade, da pobreza e da misé ria ${ }^{6,7}$, explicitado por um quadro caótico ligado à desorganização social, reflexo do processo de urbanização rápido e desestruturado ${ }^{8}$.

Inseridas nesse contexto da violência que dizima e desestrutura famílias e sociedade em geral, as tipologias da violência e criminalidade nos centros urbanos do país têm repercutido no estilo de vida ena saúde da população. A exemplo do que ocorre no mundo, no Ceará não tem sido diferente.

Do ponto de vista das políticas públicas, as propostas de combate à violência ainda não conseguiram atingir seus objetivos, o qual, dentreeles, está o de promover segurança à população. Atualmente, a violência éum dos motivos de preocupação e medo no cenário nacional, a exemplo das mortes crescentes causadas pelas agressões, homicídios, acidentes de transportes, entre outras situações. Pesquisa que analisou a ocorrência de homicídios na população em geral, homicídios juvenis, óbitos por acidentes detransporte e mortes por armas de fogo nos 5.564 municípios brasileirossitua o município deFortale za no oitavo rank de mortes por homicídios, em 2006, com uma taxa de $35,4 / 100.000$ habitantes, para uma população estimada de $2.389,700^{\circ}$.

No Brasil, a violência urbana está presente em todas as grandes capitais e se evidencia nos homi- cídios, nas trocas de tiros entre o crime organizado, os presidiários e a polícia, de modo que, a sociedade, com medo, passou a modificar hábitos e instituir mecanismos de defesa e de segurança.

$A$ violência queaterroriza epreocupa a sociedade e o poder público provoca transtornos biológicos, emocionais e sociais, comprometendo o bem-estar e a qualidade de vida das pessoas ${ }^{3}$. Ao se fazer alusão às cartas da promoção da saúde, é essencial que se realize uma aval iação sistemática do impacto que as mudanças no contexto socioeconômico e político produzem. A Declaração de Jacarta reitera que os pré-requisitos para uma vida saudável são: paz, abrigo, instrução, segurança social, relações sociais, alimento, renda, direito devoz das mulheres, um ecossistema estável, uso sustentável dos recursos, justiça social, respeito aos direitos humanos e equidade ${ }^{10}$.

Considerando a falta de ações efetivas de combate à violência do ponto de vista governamental, as organizações não governamentais passaram a searticular para minimizá-la. Essas entidades compactuam com a conscientização da sociedade no combate à violência urbana eà impunidade.

A violência origina medo e insegurança, ameaça à li berdade e à integridade física, moral e social das famílias, dificultando a busca de soluções equilibradas, justas e humanas. Descortinar esse contexto, na trajetória de "recuperação" de famílias que perderam pessoas vitimadas pela violência urbana, possibilita debates nos espaços de participação social do Sistema Ú nico de Saúde (SUS), viabilizando e mobilizando as pessoas, no alcance da promoção da saúde e no exercício de uma cidadania responsável.

Além disso, socializar a dimensão quea violência atinge na saúde do ser humano, reforçando-a como fator condicionante ou determinante do adoecimento, baliza a reorientação de uma prática social, aperfeiçoando um olhar investigativo, uma escuta atenta e ações interdisciplinares.

Ao compreender que as produções acadêmicas devem contribuir para tornar o problema mais explícito, acredita-sequeérelevanteinvestigar como as famílias vivenciam o impacto da violência na qualidade de vida.

Dessa forma, visando contribuir com reflexões acerca dessa problemática, bem como compreender a dinâmica dos problemas causados pela violência nas famílias, esse estudo tem o objetivo de descrever o impacto da violência na qualidade de vida defamílias atendidas na Associação de Parentes e Amigos Vítimas da Violência (APAVV), em Fortaleza, Ceará.

Para situar o leitor, tem-se quea APAVV é uma entidade não governamental que oferece apoio ju- 
rídico, psicoemocional e sociocultural às famílias que perderam um entequerido, por algum tipo de violência. Essa ONG procura despertar a consciência da sociedade cearense na busca de soluções para minimizar a violência e inverter a lógica da impunidade.

\section{Metodologia}

Trata-se de um estudo de caso ${ }^{11}$ desenvolvido com famílias que buscaram suporte na APAVV entre julho de2004 emarço de2005. Os critérios deinclusão das famílias participantes foram: residir em Fortaleza (CE), ter pelo menos um ente querido vitimado pela violência, cujo desfecho resultou em óbito ou sequela, participar das atividades da APAVV e concordar em participar do estudo. Atendendo a esses critérios, cinco famílias concordaram em participar do estudo; porém, não houve participação de pais e irmãos nas entrevistas (as mães se colocaram mais disponíveis), o que poderia evidenciar a opinião masculina. Desse modo, os depoimentos foram frutos das percepções de mulheres/mães de filhos e filhas vitimados pela violência.

A coleta de dados, sequenciada e dependente, seguiu às fases exploratórias, de delimitação do estudo e de análise de dados ${ }^{11}$. $\mathrm{N}$ a fase exploratória, houve o primeiro contato com a ONG e com as famílias, com apresentação dos objetivos do estudo, participação nas reuniões e nos eventos da APAVV, bem como a realização da pesquisa documental. $\mathrm{Na}$ fase de delimitação, as famílias foram selecionadas, agendando-se as datas das entrevistas, que foram gravadas e transcritas, na íntegra.

Duas entrevistas foram realizadas na instituição e três na residência das famílias, sendo norteadas por questões que buscaram descrever como ficou a vida da família após a violência sofrida e qual o impacto dessa violência na qualidade de vida familiar. Para preservar a identidade das participantes, usamos codinomes, tais como: "Paz", "Força”, “Vontade”, “Esperança” e "Perseverança”, apesar dos sentimentos de pesar, luto, dor e desesperança que permeavam as colocações das entrevistadas. Contudo, optou-se por utilizar codinomes paradoxais, porque todas essas mulheres demonstraram o ensejo de transformar essa situação de perda do ente querido em luta por um mundo mais justo e humano.

Os dados foram analisados por categoria temática ${ }^{12}$; essa modalidade apropria-se de leitura flutuante, da identificação de categorias por meio das convergências ou das divergências dos discursos dos sujeitos, da elaboração da temática do es- tudo. A pós a análise, emergiu a categoria que convergiu para o tema: impacto da violência na saúde.

0 projeto de pesquisa foi aprovado pelo Comitê de Ética e Pesqui sa da Universidade de Fortaleza com o parecer $n^{\circ}$ 126/2004 e pelos dirigentes da instituição.

\section{Resultados}

0 impacto da violência na qualidade de vida de famílias quevivenciaram essefenômeno seevidenciou na voz de mães queperderam filhos ou filhas jovens, como também de uma mulher que foi vítima da violência intrafamiliar. 0 tempo decorrido entreessas perdas oscilava entre seis meses e dois anos e a maioria deu-se por homicídio, latrocínio, acidente de trânsito, envolvendo pessoas de classe socioeconômica ecultural diferenciada, da cidade deFortale za, Ceará. As entrevistadastinham entre 35 e 50 anos, duas possuíam ensino superior, duas, ensino médio euma, ensino fundamental. Trêseram donas decasa, uma era empresária e outra, profissional liberal.

Portanto, as mulheres respondentes do estudo vivenciaram a perda de um ente querido, que de forma abrupta, cruel, incompreensível e inaceitável comprometeu a qualidade de vida com repercussões no convívio familiar.

\section{I mpacto da violência na qualidade de vida}

Nos discursos das mães, ficou notório o quadro de luto que se instala após o trauma da violência e que perdura por longo período de tempo. Essas se confessaram debilitadas, vulneráveis ese percebem, muitas vezes, incapazes de gerir as próprias vidas.

Afastam-se do trabalho e do convívio social, exacerbam-se sentimentos de perda, abandono, revolta e impotência, que desencadeiam atitudes agressivas, aparecimento ou agravamento de doenças, sendo a hipertensão arterial e a depressão, as mais referidas.

Outras repercussões na saúde, associadas ao impacto emocional na percepção dos sujeitos, foram: labirintite, anorexia, obesidade, insônia, aumento do tabagismo e etilismo por integrantes da família. Outros distúrbios também foram salientados: gástricos, cardíacos, surgimento de "caroço" no útero, perda da memória, aumento do estresse e de várias fobias.

Temos que conviver com a dor ecom a saudadeÉ um sofrimento muito grandeeessa dor vai nosacompanhar até o resto da vida, pois arrancaram meu filho de mim. (Esperança) 
Fiquei hipertensa, por último. Tô com um elevado grau de labirintite nervoso. Já estou fazendo tratamento com o psiquiatra desde o primeiro mês que meu filho foi assassinado. Aí foi ruim, eu comecei a tomar um antidepressivo e comecei a me acabar. (Força)

Como impacto no relacionamento familiar, o alcoolismo foi o mais citado como fuga para minimizar o sofrimento e a dor. Durante as entrevistas, muitas declararam que os companheiros passaram a ingerir bebidas al coólicas, ora paratentar esquecer o trauma que estavam vivendo, ora para dormir e deixar de pensar em violência enão sentir a ausência do ente querido. As participantes revelaram utilizar "remédios" para recompor o ânimo, para conse guir viver sem a pessoa que amavam e ainda para esquecer a violência brutal a que foi submetida.

Depois da morte do meu filho, meu marido passou a beber muito mais, olha, até ser agressivo, não de bater, mas de ser impaciente e responder de maneira agressiva. 0 pensamento deleéassustador porqueàs vezes ele fala assim: "eu posso matar também, não mataram meu filho?" Acha também que a pessoa que assassinou meu filho tem que morrer, assim ele ficou. E ele bebe, eu acho que ele, já bebe pra dormir entendeu? (Paz)

N esse contexto, os filhos também se revoltam com a situação, demonstrando sentimentos devingança e ódio. As atitudes dos filhos, antes da morte violenta na família, que eram percebidas e conhecidas pelos pais, assumem, agora, reações imprevisíveis, caracterizadas pelo nervosismo, pela inquietação, pelo medo ou pela coragem exacerbados. Os pais controlam os filhos, esses se sentem "sufocados", rejeitam as re-orientações, a comunicação, o entendimento e os relacionamentos se tornam difíceis, com "brigas" frequentes.

M inha família toda ficou estremecida, todos ficaram com um comportamento diferente depois da violência contra minha filha, estamos tentando estabilizar a nossa vida, é difícil, mas com a ajuda das pessoas que nos amam vamos conseguir. (Perseverança)

Entre paisefilhos, identificam-se relacionamentos conturbados, sensação de impotência, culpa, medo e insegurança quanto ao futuro no âmbito familiar. Esses jovens sofrem com a perda do irmão e com o sofrimento da família, principalmente da mãe.

Esse meu outro menino, esse de quinze anos. Ficou muito nervoso. O Iha, eu fiquei doente, eu sofro com isso. A gente não pode fazer nada, que ele fica com raiva, com muita raiva. $\mathrm{N}$ ão há mais conversa com meu marido e ele porque brigam de nervosismo. $M$ inha casa ficou um clima tenso que antes da morte do meu filho não existia. (Paz)
0 meu filho adolescenteéquetá passando por um momento difícil e eu não sei como lidar. Ele se isola, não conversa, ficou um menino estranho. M eu filho dizia para meu marido: "eu não posso perder minha mãe. Ela está adoecendo por causa disso". (Força)

As famílias constatam que o seu "dia a dia" está sendo permeado pelo medo e pela insegurança. É consenso, para elas, que a solidariedade entre as pessoas sofreu um declínio acentuado com a violência, fato esse fácil de ser comprovado nos "retratos midiáticos" dos acontecimentos sociais. Para elas, a situação é mais delicada e de difícil solução, uma vez que a área de abrangência atinge, também, o campo da saúde.

Com a sensação de completa insegurança, essas pessoas passam a trocar de moradia com frequência, ficam temerosas ao sair de casa e ao frequentar lugares públicos. 0 convívio com os amigos e o lazer são postos em segundo plano e, muitas vezes, esquecidos.

Somos prisioneiros, não temos mais liberdade, quando saímos de casa temos que nos defender, não somos livres. (Vontade)

$\mathrm{H}$ oje as pessoas têm medo de ajudar as pessoas porqueninguém sabeseaquela pessoa realmenteestá pedindo ajuda ou vai nos assaltar. (Perseverança)

M eu filho foi a vítima, e nós somos a vítima também, aí se tornou um medo maior. Simplesmente não saio tranquila nem eu nem minha família. Tenho tanto medo da violência que já mandei trancar minha casa toda: coloquei cerca, coloquei cachorro e, mesmo assim, morro de medo. (Paz)

Foi constatado que os sentimentos das pessoas mudam com o passar do tempo quando fazem parte deuma ONG. Inicialmente, elas chegam debilitadas com a violência ocorrida, com sentimentos de ódio e pensamentos de vingança. Posteriormente, com o envolvimento e a ajuda de outras famílias que vivem situações semel hantes, o ódio e a sede de vingança vão se transformando em solidariedade, amor e esperança de um mundo melhor.

Olhando por tudo o que eu já passei, parece assim, que foi uma coisa que eu tinha que passar, pra eu poder lutar por alguma coisa. N ão ficar acomodada. Foi através da dor que passei a ver que sempre tem uma coisa que vem para o bem da pessoa. Poisé, luto pela minha causa e pela causa dos outros, porque eu aprendo mais. (Paz)

Aqui me sinto mais calma e com mais força para enfrentar o dia a dia sempre há uma melhora. Sabemos eaprendemostambém com outrasfamílias a lidar com essa tragédia em nossas famílias. (Perseverança)

Foi aqui na APAVV que comecei a reagir, participo das reuniões e me sinto melhor, estou fazendo alguma coisa para mudar, era o que todo mundo 
deveria fazer e não deixar que aconteça alguma coisa para tentar mudar. (Força)

Percebe-se com este estudo que a luta das muIheres vitimadas pela violência passa a ser orientada pela busca de seus direitos e conscientização de que podem transformar a realidade por meio de ações concretas e coordenadas, visando ao fim da impunidade, a principal causa da violência. Estas deixam de lado o estado de prostração e imobilismo elutam com coragem e destemor na conquista de uma vida saudável e com mais segurança.

\section{Discussão}

O estudo discorreu sobre o impacto da violência na saúde das famílias que participavam de uma ON G no combate à violência e à impunidade. $0 \mathrm{~s}$ depoimentos das participantes corroboram com a construção dinâmica do conceito de saúde, cada vez mais evidenciando sua interface com o momento histórico, político e social, bem como a urgência de se efetivar parcerias com a sociedade civil nas soluções de problemas que dizimam bens coletivos, tais como saúde, segurança, paz, lazer.

0 alcance desses atos violentos na saúde e no cotidiano das famílias se manifesta por mudanças de hábitos e atitudes, tornando-se gênese do processo de adoecimento físico e mental, ou ampliando-o.

Q uando o ser humano internaliza sentimentos negativos e controversos, eletem a sua saúde comprometida, porque passa a "somatizar" as suas culpas, os seus medos, as suas angústias e os seus segredos. N esse caso, a doença emocional será somatizada, por meio detremedei ras, "suadeira", tensões musculares, arritmias cardíacas, sensibilidadecutânea ealterações psicoemocionais, tais como sentimentos depressivos, nervosismo, ansiedade, transtornos alimentares ${ }^{13}$.

Ficou evidente que a morte advinda de causa violenta inesperada afeta abruptamente a estrutura familiar, pois não é como a morte "digerida" por meio do acompanhamento de um processo mórbido, ou da velhice, culturalmente compreendidos, como sendo naturais. Dependendo do vínculo estabelecido com a pessoa falecida e da personalidade do enlutado, o mundo desse último pode ruir, gerando o pavor, a desorientação, 0 choque e 0 desespero ${ }^{14}$.

Sobre verbalizações dos sentimentos de perda e pesar, este estudo concorda com achados anteriores em queseinvestigou sobre pais em luto, pelos quais a perda de filhos foi relatada como gênese de uma desorganização emocional intensa, de episó- dios de depressão, melancolia e certo desapego à vida ${ }^{6}$. No intuito decorroborar ainda com os achados dessa pesquisa, $\mathrm{M}$ inayo $^{3}$ reforça que, mundialmente, os óbitos infligidos por outros (ou autoinfligidos) se configuram como sério problema social etêm intensas repercussões na saúde pessoal ecoletiva.

Cada ato de violência provoca nas famílias enlutadas a sensação de uma perda irreparável e o sentimento de revolta e de clamor por justiça, com muito sofrimento edor insuportáveis, sendo visualizados nos discursos dessas mulheres/mães. Como consequência, as vítimas indiretas têm a saúde comprometida, tornam-se fármaco-dependentes e arcam com os efeitos adversos dessa me dicalização que agravam os problemas de saúde.

A vida dessas pessoas passa a ser um pesadelo, em que as doenças vão surgindo, alternando-se com estados de extrema tristeza. A pegam-se às lembranças e se descobrem impotentes diante do vivido. A literatura retrata que o significado da perda de um ente querido origina o luto e esse é uma crise que atinge $o$ indivíduo, sua família e os sistemas mais amplos da sociedade ${ }^{3,6}$.

Portanto, o comportamento desses sistemas interfere no enfrentamento da crise do luto, pelo indivíduo que a vivencia ${ }^{14}$. Esse contexto de desorganização emocional favorece a intensificação de hábitos prejudiciais à saúde familiar e tende a aumentar a ingestão de álcool, devido a situações cotidianas quefavorecem o estresse, o que podeinduzir à dependência, com seus efeitos indesejávei ${ }^{15}$.

Ao se investigar sobre vidas errantes ealcoolismo na cidade de Assis (SP), identificou-se que o uso do álcool está associado à necessidade de esquecer problemas do passado, evadir as sensações de angústia e conflitos em que se vive frente à realidade, também corroborado com os resultados deste estudo ${ }^{16}$.

Outro ponto a considerar na pesquisa foi a identificação de relacionamentos conturbados, a sensação de impotência, culpa, medo e a insegurança quanto ao futuro da família. N esse contexto, os filhos sofrem com a perda do irmão, consternação da família, principalmente da mãe.

A família assume, como tarefa, a produção e a imposição de padrões de comportamento, papéis e funções a serem utilizados no cotidiano social e sofrem com a perda de um ente familiar pela violência. Essas perdas ocasionam diversas mudanças, não somente em nível psicológico, como também físico, sexual e até mesmo nas maneiras de se comportar, acarretando sérios prejuízos. Isso porque até o processo de comunicação e relacionamento interpessoal é afetado drasticamente ${ }^{17}$. 
A violência desperta no local de moradia sentimentos que se interligam com os elementos integrantes de identidade, tornando-se, também, ele mentos importantes na sua constituição. 0 medo pode aparecer de forma imaginária, como uma proteção, até que se tenha certeza de que émelhor temer e ficar à distância.

0 medo ea insegurança tendem a desencadear no indivíduo fortes alterações emocionais, principalmente no que concerne às relações interpessoais. Dificilmente, o vitimado conseguirá manter uma relação afetiva sem desconfiança, insegurança e medo ${ }^{17}$.

Esse medo é apenas uma das manifestações do vivenciar a violência, sobretudo hoje, nas grandes regiões metropolitanas, ondeseconcentram $75 \%$ de todas as mortes por essa causa. É no âmbito dessas questões que se trabalha com o objeto "violência" e seu devido impacto na saúde - articulando saberes de várias disciplinas, contribuições de vários campos profissionais, com a certeza de que apenas uma abordagem intersetorial e interdisciplinar não consegue abranger a problemática em questão 5 .

Como o ser humano é, também, o resultado da interação entre o meio social (físico) e o psíquico (mental), seu comportamento pode sofrer alterações a partir do contato com a violência. Violentar o cidadão é arrancá-lo da sua dignidade física, mental, social, no sentido mais amplo que essa tríade possa expressar. N esse sentido, é indiscutível o impacto quea violência tem acarretado à saúde do ser humano.

Saúde, como preconiza a Carta de Ottawa, deve ser compreendida como um recurso para a vida, e não como objetivo deviver. Ela éum grande “insumo" para o desenvolvimento pessoal, econômico e social, assim como uma importante dimensão da qualidade de vida. Fatores políticos, econômicos, socioambientais, comportamentais e biológicos podem favorecer ou prejudicar a saúde ${ }^{10}$.

Entretanto, ao conhecerem o trabal ho social eo atendimento interdisciplinar desenvolvido pelaAPA$V V$, os parentes e os amigos das vítimas aprendem a reagir e superar o fato. Aos poucos vão adquirindo segurança em si mesmos, resgatando a auto-estima e a cidadania, restaurando o bem-estar evoltando a socializar-se, reorganizando a vida familiar.

Essas famílias se unem na luta por justiça e no reconhecimento dos direitos de cidadania, mobilizando a sociedade na busca de medidas eficazes para o enfrentamento e redução da violência.

\section{Consideraçõesfinais}

A partir desse estudo, percebeu-se a repercussão da violência na saúde e no cotidiano de famílias que perderam pessoas em decorrência desse fenômeno. Na maioria dessas famílias, houve mudanças no comportamento de seus membros, aproximando-se do álcool, do tabagismo, do uso de fármaco-dependentes, além de romper com o equilíbrio ecom a harmonia dos relacionamentos familiares esociais.

Essas famílias confessaram-se frágeis, inseguras e adoecidas, física, mental e socialmente, mas, paradoxalmente, apropriaram-se de uma força para organizar e lutar pela inversão da lógica da impunidade.

Enquanto assumiram a "condição de vítima", essas famílias se mantiveram doentes na corporeidade e emoções. Ao re-assumirem sua condição cidadã, acreditaram queépossível diminuir o avanço da violência em Fortaleza e o fim da impunidade para os criminosos, contanto que a sociedade esteja atuante, vigilante e consciente desse desafio. 


\section{Colaboradores}

LJES Vieira orientou todas as etapas da elaboração da dissertação, redação, revisão parcial e final do artigo. M LV Arcoverde trabalhou na concepção teórica, elaboração, execução e redação final da pesquisa. RC Ferreira colaborou na revisão bibliográfica para redação do artigo e revisão final. AVM Fialho, AMJ Pordeus e M AL Araújo contribuíram na revisão crítica do texto.

\section{Agradecimentos}

Este trabalho contou com auxílio financeiro da Fundação Cearense de Amparo eApoio à Pesquisa (FUNCAP) e auxílio material e financeiro do Conselho Nacional de Desenvolvimento Científico e Tecnológico (CN Pq), entidadegovernamental brasileira promotora do desenvolvimento científico e tecnológico, Processo n 50.4458/2004-3.

\section{Referências}

1. Gawryszewski VP, Kahn T, Jorge M HP de M. Informações sobre homicídios e sua integração com 0 setor saúde e segurança pública. Rev. Saude Publica 2005; 39(4):627-633.

2. Concha-Eastman $A, M$ alo $M$. From repression to prevention against violence: a challenge posed to civil society and the health sector. Cien Saude Colet 2006; 11(2):339-348.

3. M inayo MCS. Violência: um problema para a saúde dos brasileiros. In: Brasil. M inistério da Saúde. Secretaria de Vigilância em Saúde. Impacto da violência na saúde dos brasileiros. Brasília: M inistério da Saúde; 2005.

4. Schraiber LB, D'Oliveira AFPL, Couto MT. Violência e saúde: estudos científicos recentes. Rev. Saude Publica 2006; 40(spe):112-120.

5. M inayo MCS. A violência dramatiza causas. In: M inayo M CS, Souza ER, organizadoras. Violência sob o olhar da saúde: a infrapolítica da contemporaneidade brasileira. Rio de Janeiro: Fiocruz; 2003. p.23-48.

6. Silva SF. Crescimento da violência urbana: as grandes cidades estão diante de uma epidemia social? Divulgação em Saúde para Debate 2004; 30:10-14.

7. Nunes M, Paim JS. Um estudo etno-epidemiológico da violência urbana na cidade de Salvador, Bahia, Brasil: os atos de extermínio como objeto de análise. Cad Saude Publica 2005; 21(2):459-468.

8. M orais R. 0 que é violência urbana. 6 a ed. São Paulo: Brasiliense; 1995.

9. Waiselfiz JJ. Mapa da violência dos municípios brasileiros - 2008. 1a ed. Brasília: RITLA/M inistério da Saúde/M inistério da Justiça; São Paulo: Instituto Sangari; 2008.

10. Brasil. M inistério da Saúde. Promoção da Saúde. Declaração de Alma-Ata. Carta de Ottawa. Declaração de Ade laide. Declaração de Sundsvall. Declaração de Santa Fé de Bogotá. Declaração de Jacarta. Rede de M egapaíses. Declaração do M éxico. Brasília: Ministério da Saúde; 2001.

11. Yin RK. Estudo de caso: planejamento e métodos. 2a ed. Porto Alegre: Bookman; 2001.

12. M inayo MCS. 0 desafio do conhecimento: pesquisa qualitativa em Saúde. 3a ed. São Paulo: Hucitec; Rio de Janeiro: ABRASCO; 1996.

13. Goleman D. Inteligência emocional: a teoria revolucionária que redefine o que é ser inteligente. $29 \mathrm{a}$ ed. Rio de Janeiro: Objetiva; 1995.

14. Domingos $B, M$ aluf $M R$. Experiências de perda e de luto em escolares de 13 a 18 anos. Psicol Reflex Crit [periódico na Internet]. 2003 set-dez [acessado 2006 set 20]; 16(3):[ cerca de 3 p.]. Disponível em: http:// www.scielo.br/pdf/prc/v16n3/v16n3a16.pdf

15. Sayette MA. Does drinking reduce stress? Alcohol Research \& H ealth 1999; 23(4):250-255.

16. Nascimento EC do, Justo JS. Vidas errantes e alcoolismo: uma questão social. Psicol Reflex Crit 2000; 13(3):529-538.

17. Barros HM, Oliveira EM, Jorge MSB. Violência sexual: sofrimentos, marcas e enfrentamento de um grupo de adolescentes. Sustentação 2003; IV (11):20-34. 